www.jmscr.igmpublication.org

Impact Factor (SJIF): 6.379

Index Copernicus Value: 79.54

ISSN (e)-2347-176x ISSN (p) 2455-0450

crossrefDOI: https://dx.doi.org/10.18535/jmscr/v7i1.29

Journal Of Medical Science And Clinical Research

IGM Publication

An Official Publication of IGM Publication

\title{
Role of ultrasound and MDCT in evaluation of patients with acute abdomen
}

\author{
Authors \\ Dr Rupinder Singh ${ }^{1}$, Dr Harsimar ${ }^{2}$, Dr Harneet Narula ${ }^{3}$, Dr Amit Mittal ${ }^{4}$ \\ ${ }^{1}$ Associate Professor, Department of Radiodiagnosis and Imaging, M.M. Institute of Medical Sciences and \\ Research, Mullana, Ambala \\ ${ }^{2}$ Resident, Department of Radiodiagnosis and Imaging, M.M. Institute of Medical Sciences and Research, \\ Mullana, Ambala \\ ${ }^{3,4}$ Professor, Department of Radiodiagnosis and Imaging, M.M. Institute of Medical Sciences and Research, \\ Mullana, Ambala \\ Corresponding Author \\ Dr Amit Mittal \\ Professor, Department of Radiodiagnosis and Imaging, M.M. Institute of Medical Sciences and Research, \\ Mullana, Ambala, India \\ Ph: 8059931477, Email: amitmittalmri@gmail.com
}

\begin{abstract}
Aims And Objectives

1. To compare MDCT findings with USG findings in patient with acute abdomen.

2. To compare results of MDCT findings with operative findings / clinical outcome of patients.

Materials and Methods: Fifty patients with signs and symptoms suggestive of acute abdominal pain referred from various wards and outpatient departments were included in the study. Patients with acute abdominal pain were evaluated with both ultrasonography and computed tomography and the results were evaluated and compared.

Results: In our study Majority of cases were of pancreatitis, ureteric calculus and cholecystitis. USG diagnosis was consistent with Final diagnosis in $70 \%$ (35patients) of cases out of 50 patients. Diagnosis of MDCT was consistent with final diagnosis in 47patients with accuracy of MDCT in current study of 94\%.USG findings were compared with MDCT findings and USG findings were in concordance with MDCT findings in 37 patients (74\%). MDCT findings were compared with operative findings and 33 patients were operated out of 50 cases, among 33 operated cases, operative findings were similar in 28patients (84\%). Pre CT diagnosis was compared with Post CT diagnosis and it was found that diagnosis was changed in 14 patients(28\%) and diagnosis remained unchanged in 36cases (72\%). Next Pre-CT management strategy was compared with actual Post-CT management strategy. In our study, after doing CT, management strategy was changed in 19patients (38\%cases).

Conclusion: From our study, it could be concluded that MDCT is an effective imaging modality with results that have a positive effect on the management of many patients with acute abdominal pain. Radiation exposure is a drawback of MDCT but US may serve as an initial diagnostic test. CT may then be reserved for patients with non-diagnostic US results.

Keywords: acute abdomen, USG, CT.
\end{abstract}




\section{Introduction}

Acute abdomen is referred to as a condition characterized by severe pain in abdomen which develops in duration of hrs and commonly explains acute abdominal pain in a group of patients who are extremely unwell and complains of rigidity and tenderness in abdomen. ${ }^{1,2}$ Acute pain in abdomen is a common and chief presenting complaint in patients admitted in emergency department which can be compared to numerous diagnosis. The unexpected onset of severe abdominal pain characterizing the "acute abdomen" needs urgent identification of lifethreatening pathology to provide timely curative strategy. In the patients presenting with acute pain in abdomen the role of conventional radiography has been surpassed and this technique has only role in patients presenting with obstructed bowel ${ }^{2}$. When cost of technique and radiation exposure is main problem then in such cases possible option is to carry out US as initial procedure in subjects with acute abdomen with MDCT carried out in patients with non-diagnostic US ${ }^{2}$. CT is found out to be more informative and accurate, its findings have been known to have drastic effect in managing the patients with acute pain in abdomen. Its cost effectiveness in patients with acute appendicitis was considered and hence CT was found out to be a cost effective modality. As a result CT can be considered as primary imaging procedure for diagnosis of acute abdomen, except in those subjects who are clinically suspecting of having acute cholecystitis in such patients we carry out US as primary imaging investigation of choice. ${ }^{(2)} \mathrm{CT}$ should be carried out in US positive cases, in symptomatic patients with negative US scans and in patients with suboptimal scan.

\section{Material and Methods}

Presently study was carried out in Department of Radio-diagnosis, M.M. Institute of Medical Sciences and Research, Mullana, Ambala. Fifty patients with signs and symptoms suggestive of acute abdominal pain referred from various wards and outpatient departments were included in the study. Patients with acute abdominal pain were evaluated with both ultrasonography and computed tomography. Ultrasonography was done first followed by computed tomography in ultrasonography (US) positive cases, in symptomatic patients with negative US scans and in patients with suboptimal scan.

\section{Exclusion criteria}

Previous abdominal surgery within 4 weeks.

Abdominal Trauma

Pregnancy

Allergy to iodinated contrast media

Severe renal insufficiency

Equipment

Ultrasonography (USG)

HD 15(Philips medical systems, USA) with convex and linear probes.

\section{Computed Tomography (CT)}

128 slice multidetector spiral CT (Philips Ingenuity)

\section{Computed Tomography (CT)}

CT scan was performed on multidetector CT Ingenuity (Philips medical system, USA).Oral contrast was used depending upon clinical situation. Patients were made to lie in the supine position on the couch. Scout image of abdomen were taken. Non contrast CT was done wherever required. Then contrast enhanced CT area was covered from diaphragm to pubic symphysis and slices were taken with pitch 0.765 , collimation $640 \times 625,5 \mathrm{~mm}$ thickness, $5 \mathrm{~mm}$ increment at 120 $\mathrm{KV}$ and 300 MAS after intravenous administration of $80-120 \mathrm{ml}$ of non ionic contrast medium (iohexol) containing $300 \mathrm{mg} / \mathrm{ml}$ of iodine. The amount of contrast varied according to patient's body weight, clinical and renal status. Delayed scan were done wherever required.

Findings of CT and US of acute pain abdomen cases were analyzed in the prospective manner to evaluate their use as a diagnostic modality and also to determine their contribution in management of patient. Findings of ultrasonography and Computed tomography were correlated with one another and further compared 
and correlated with clinical outcome / or operative findings (wherever performed).

\section{Results}

Age distribution in our series ranged from7 years to 85years.Maximum number of patients were between 46 to 60 years of age group (30\%). There were $68 \%$ males and $32 \%$ females in our study. In our study, there was broad spectrum of diseases, presenting as acute abdomen with maximum percentage of patients of Pancreatitis(18\%) followed by ureteric calculus(14\%), cholecystitis $(12 \%)$, ischemia $(8 \%)$, volvulus $(8 \%)$, perforation (8\%), appendicitis $(8 \%)$ (Table-1).

Table I Final diagnosis of Patients $(\mathrm{n}=50)$

\begin{tabular}{|l|c|c|}
\hline Diagnosis & $\begin{array}{c}\text { Number of } \\
\text { Patients }\end{array}$ & centage(\%) \\
\hline Pancreatitis & 9 & 18 \\
\hline Ureteric Calculus & 7 & 14 \\
\hline Cholecystitis & 6 & 12 \\
\hline Ischemia & 4 & 8 \\
\hline Volvulus & 4 & 8 \\
\hline Perforation & 4 & 8 \\
\hline Appendicitis & 4 & 8 \\
\hline Diverticuiltis & 3 & 6 \\
\hline Pelvic Masses & 2 & 4 \\
\hline Large gut obstruction & 1 & 2 \\
\hline Aortic aneurysm (rupture) & 1 & 2 \\
\hline Mucocele Appendix & 1 & 2 \\
\hline Peptic ulcer disease & 1 & 2 \\
\hline Liver abscess & 1 & 2 \\
\hline Intussusception & 1 & 2 \\
\hline Mesenteric lymphadenitis & 1 & 2 \\
\hline & 50 & \\
\hline
\end{tabular}

Fifty patients underwent USG and results of USG diagnosis were also confirmed with final diagnosis. In our study, USG diagnosis was consistent with Final diagnosis in 70\% (35patients) of cases. Out of 9 cases of pancreatitis, 6 cases matched the final diagnosis and 3 cases were disconcordant due to obscured pancreas in 2 cases and in one case pancreas appeared normal on US. There were 7 cases of ureteric calculus, all of which were correctly diagnosed on US. 6 cases of cholecystitis was noted, findings of all the 6 cases matched the final diagnosis. In case of ischemia there were total 4 cases out of which only 1 case matched the final diagnosis, rest 3 cases did not match the diagnosis. There were 4 cases of volvulus ( 3 were correctly diagnosed on US) out of which 2 cases were of gastric volvulus, one of caecal and one of small gut volvulus. One case of gastric volvulus was diagnosed giving positive peanut sign on US, however another case of gastric volvulus could not be diagnosed on ultrasound as patient was not cooperative enough so GE junction and stomach was not well visualized. Fluoroscopy, radiography and CT scan are considered investigations of choice for volvulus. 4 cases of perforation were there out of which only 2 cases were correctly diagnosed on US. In rest 2 cases one of case showed thickening of gut loops with ascites on US which turned out to be perforation on CT. Another case on US showed ascites with excessive gas shadowing and even CT showed thickening of stomach wall with ascites without any e/o perforation but it was found out to old perforation with very small rent in body of stomach when operated. Out of 4 cases of appendicitis only 1 case was not correctly diagnosed on US. Rest 3 cases matched the final diagnosis. CT scan correctly diagnosed it to be appendicitis. All 3 cases of diverticulitis were not diagnosed on US. One case showed thick walled gut loops with intergut fluid, another showed cystitis and last one showed normal study on US. Diagnosis was made when CT scan was carried out.1 case of large gut obstruction could not be visualized on US . US scan showed excessive gas shadowing in abdomen. This case was correctly diagnosed on CT. 1 case of peptic ulcer disease was not diagnosed on US . US showed thickening of duodenal wall. Further CT scan was carried out. CT showed only duodenitis with ascites .Operative findings revealed it to be a perforated duodenal ulcer. Endoscopy is considered modality of choice for diagnosing peptic ulcer disease. 
Table II Comparison of USG and MDCT findings with final diagnosis $(n=50)$

\begin{tabular}{|c|c|c|c|}
\hline Diagnosis & $\begin{array}{c}\text { USG } \\
\text { Diagnosis } \\
\text { Concordance } \\
\text { with final } \\
\text { diagnosis }\end{array}$ & $\begin{array}{c}\text { MDCT in } \\
\text { Diagnosis } \\
\text { Concordance } \\
\text { with final } \\
\text { diagnosis }\end{array}$ & $\begin{array}{c}\text { Final } \\
\text { Diagnosis }\end{array}$ \\
\hline Pancreatitis & 6 & 8 & 9 \\
\hline UretericCalculus & 7 & 7 & 7 \\
\hline Cholecystitis & 6 & 6 & 6 \\
\hline Ischemia & 1 & 4 & 4 \\
\hline Volvulus & 3 & 4 & 4 \\
\hline Perforation & 2 & 3 & 4 \\
\hline Appendicitis & 3 & 4 & 4 \\
\hline Diverticuiltis & 0 & 3 & 3 \\
\hline PelvicMasses & 2 & 2 & 2 \\
\hline Large gut obstruction & 0 & 1 & 1 \\
\hline $\begin{array}{c}\text { Aortic } \\
\text { aneurysm(Rupture) }\end{array}$ & 1 & 1 & 1 \\
\hline Mucocele Appendix & 1 & 1 & 1 \\
\hline Peptic ulcer disease & 0 & 0 & 1 \\
\hline Liver abscess & 1 & 1 & 1 \\
\hline Intussusception & 1 & 1 & 1 \\
\hline $\begin{array}{c}\text { Mesenteric } \\
\text { lymphadenitis }\end{array}$ & 1 & 1 & 1 \\
\hline & $\mathbf{3 5}$ & $\mathbf{4 7}$ & $\mathbf{5 0}$ \\
\hline
\end{tabular}

Comparison of MDCT diagnosis with Final diagnosis was done after the final diagnosis was made after getting other investigations and histopathological confirmations. Diagnosis of MDCT was consistent with final diagnosis in 47 patients with accuracy of MDCT in current study of $94 \%$. MDCT could not detect one case of pancreatitis, one case of peptic ulcer disease and one case of perforation. In case of pancreatitis CT revealed pancreas to be normal and showed peripancreatic lymphadenopathy with suspicion of mesenteric ischemia, however on laboratory investigations amylase, lipase were found elevated. CT could not detect pancreatitis in this case because it was very initial stage of pancreatitis.

In case of peptic ulcer disease it was perforated duodenal ulcer which was not detected on CT. CT showed only duodenitis with ascites. Operative findings revealed it to be a perforated duodenal ulcer with ulcer crater along anterior duodenal wall. However rent was very small so it was missed on CT scan. Moreover endoscopy is considered modality of choice for diagnosing peptic ulcer disease. In case of perforation stomach wall was found asymmetrically thickened with free fluid on CT however on operative findings a rent was found in fundal region. CT could not detect this case because it was small size of perforation with old sealed off perforation.

Among 50 patients, 33 patients $(66 \%)$ were operated, 12 patients (24\%) were managed conservatively and interventions like (ERCP, Catheter drainages and DJ stenting) were done in 5 patients (10\%). Among 33 operated cases, operative findings were similar in 28 patients (84\%) and operative findings were different in 5 patients (16\%). Pre-CT management strategy was asked from referring unit with probable pre-CT diagnosis. Pre-CT management strategy was compared with actual Post-CT management. In our study, after doing CT, management strategy was changed in 19 patients (38\% cases).

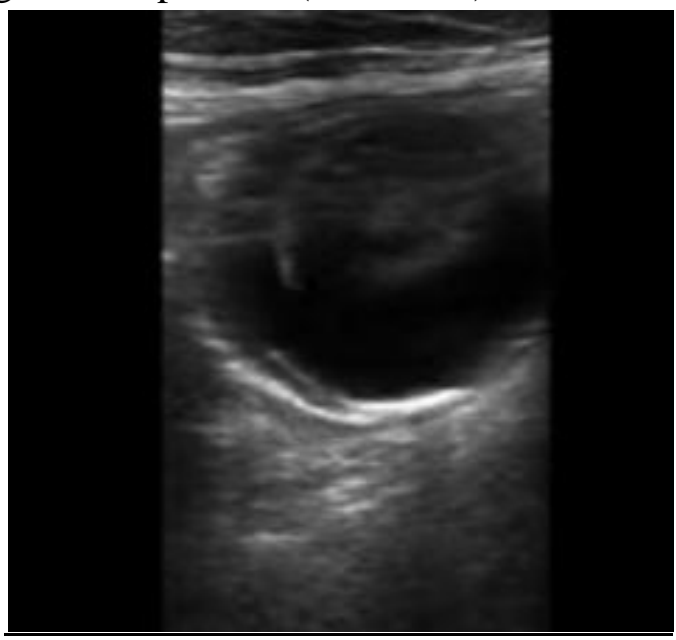

Fig-1 A Showing cystic lesion in right iliac fossa.

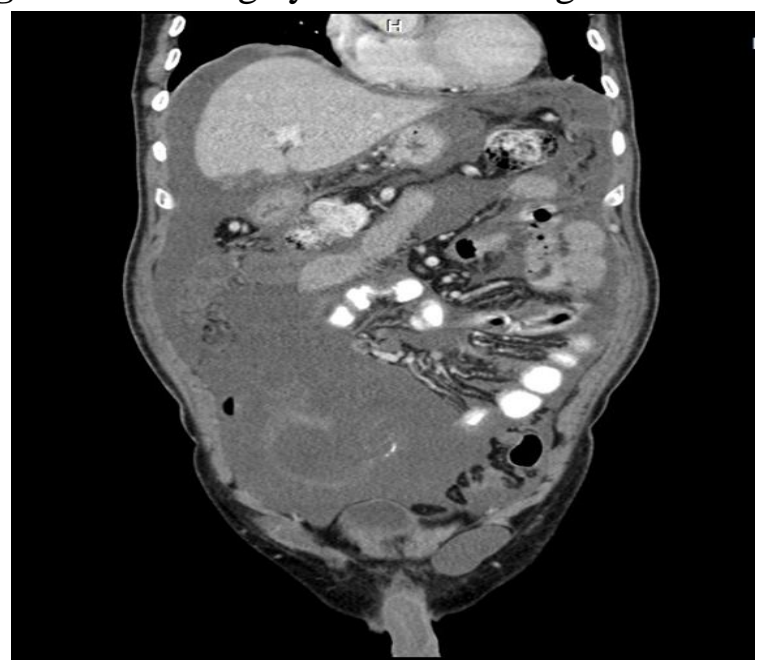

Fig-1 B shows ruptured cystic lesion in right iliac fossa with calcification in wall arising from appendix with associated significant ascites suggestive of Mucocele Appendix. 


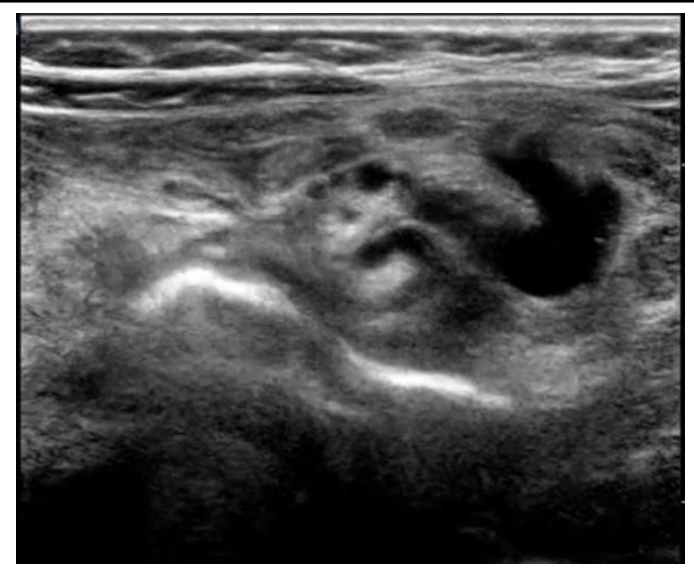

Figure-2a: Ultrasound images showing twisting of gut loops and mesentry in abdomen

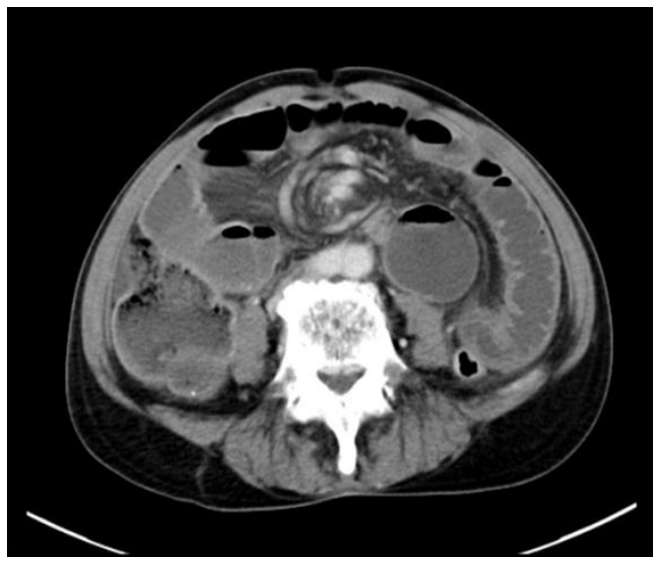

Figure-2b: CECT is showing "whirlpool Sign" with small gut obstruction suggestive of Small gut volvulus

\section{Discussion}

In our study, fifty patients underwent USG and results of USG diagnosis were also confirmed with final diagnosis. In our study, USG diagnosis was consistent with Final diagnosis in 70\% (35 patients) of cases out of 50 patients. In one study by Walsh P F, Crawford D et $\mathrm{al}^{3}$,US reportedly provided useful information for $56 \%$ of patients with acute abdominal pain, and in another study by McGrath F P, Keeling F et $\mathrm{al}^{4}$ it either yielded unique diagnostic information or confirmed one of the differential diagnoses in $65 \%$ of patients. Allemann $\mathrm{F}$, Cassina $\mathrm{P}$ et $\mathrm{al}^{5}$ concluded that among 496 patients who presented with acute abdominal pain to an emergency, the proportion of patients with a correct diagnosis after clinical evaluation increasedfrom $70 \%$ to $83 \%$ after evaluation with US.
Another study carried out by Nural MS et $\mathrm{al}^{6}$ stated that when US was compared with discharge diagnosis there was concordance in $79.3 \%$ of cases.

Pablo R. Ros, James E et $\mathrm{al}^{7}$ stated that US is the least appropriate imaging modality when high -or low- grade bowel obstruction is suspected. Sabina Imran $^{8}$ concluded that the accuracy of ultrasound examination in upper abdominal pain is slightly less than $50 \%$ because of its limitations in the diagnosis of gastrointestinal problems and mild urinary tract infections.

In our study, diagnosis of MDCT was consistent with final diagnosis in 47 patients with accuracy of MDCT in current study of $94 \%$. 3 cases did not match the final diagnosis which include one case each of pancreatitis, perforation and peptic ulcer disease. Tsushima $\mathrm{Y}$ et $\mathrm{al}^{9}$ conducted effect of contrast enhanced computed tomography on diagnosis and management of acute abdomen study on 125 patients presenting with acute abdominal symptoms. They concluded that MDCT diagnoses were consistent with the final diagnoses in 116 patients (92.8\%). Andrew B. Mac Kersie, Michael J. Lane et al ${ }^{10}$ studied on 91 patients and concluded that, unenhanced helical CT yielded an overall sensitivity, specificity, and accuracy of $96.0 \%, 95.1 \%$, and $95.6 \%$, respectively.

In case of pancreatitis CT revealed pancreas to be normal and showed peripancreatic lymphadenopathy with suspicion of mesenteric ischemia, however on laboratory investigations amylase, lipase was found elevated. CT could not detect pancreatitis in this case because it was very initial stage of pancreatitis. This result matched the study carried out by Nural M S et $\mathrm{al}^{6}$ who stated that laboratory and clinical findings play an important role specially in early stages of pancreatitis. In case of perforation stomach wall was found asymmetrically thickened with free fluid on CT however on operative findings a rent was found in fundal region. CT could not detect this case because it was small size of perforation with old sealed off perforation. Our result was similar to study carried out by $\mathrm{J}$ Sherck et $\mathrm{al}^{11}$ and 
Maniatis $\mathrm{V}$ et $\mathrm{al}^{12}$ who stated that it is not necessary that when free air is not present then it is not perforation. There are secondary signs of perforation which include abrupt wall thickening, adjacent dirty fat density, abscess or inflammatory mass or phlegmon related to lumen and unexplained fluid in abdomen, which also indicate perforation.

In case of peptic ulcer disease it was perforated duodenal ulcer which was not detected on CT. CT showed only duodenitis with ascites .Operative findings revealed it to be a perforated duodenal ulcer with ulcer crater along anterior duodenal wall. However rent was very small so it was missed on CT scan. Fiberoptic endoscopy is considered modality of choice for diagnosing peptic ulcer disease. Endoscopy has a sensitivity of $95 \%$ according to study carried out by Mamel $\mathrm{JJ}^{13}$ . There were 4 cases of ischemia all of which were correctly diagnosed on MDCT. This was similar to study carried out by Yildirim D et $\mathrm{al}^{14}$ which stated that CT is the modality of choice for ischemia. Another study carried out by Nural M S et $\mathrm{al}^{6}$ also stated limited role of US alone in diagnosing ischemia. They added that laboratory and clinical findings plus CT is helpful in accurately diagnosing ischemia cases.

Among 50 patients in our study, 33 patients were operated; MDCT findings were consistent with operative findings in 28 patients with accuracy of $84 \%$. Weir-McCall J, Shaw A et al ${ }^{15}$ compared pre-operative CT findings with operative findings in 97 patients with accuracy varied from $78 \%$ to $93 \%$ which is similar to our study of 50 patients. HainauxB, Agneessens $\mathrm{E}$ et $\mathrm{al}^{16}$ studied 85 patients where diagnostic accuracy was $85 \%$ which was also similar to our current study.

Another study conducted by M Foinant et $\mathrm{al}^{17}$ who carried out study in 90 patients 25 out of which were scheduled and underwent surgery . 22 patients had operative findings similar to MDCT findings which had an accuracy of $88 \%$ which was also similar to our current study.

\section{Conclusion}

Prospective study on fifty patients presented with acute abdomen showed that USG may serve as initial diagnostic imaging technique with high rates of accuracy in cholecystitis, ureteric calculi and appendicitis but limited role in bowel disorders. MDCT examination as part of the management of non-traumatic acute abdomen contributes to a precise diagnosis in $94 \%$ of cases and can re-orient patient management in $38 \%$ of cases. CT is found out to be more informative and accurate, its findings have been known to have drastic effect in managing the patients with acute pain in abdomen.

CT should be carried out in US positive cases, in symptomatic patients with negative US scans and in patients with suboptimal scan.

\section{Bibliography}

1. Tsushima Y, Yamada S, Aoki J, Motojima T, Endo K. Effect of contrast enhanced computed tomography on diagnosis and management of acute abdomen. Clinical Radiology. 2002; 57: 507-13.

2. Stoker J, van Randen A, Lameris W, Boermeester MA. Imaging Patients with Acute Abdominal Pain. Radiology. 2009; 253:31-46.

3. Walsh PF, Crawford D, Crossling FT, Sutherland GR, Negrette JJ, Shand J. The value of immediate ultrasound in acute abdominal conditions: a critical appraisal. Clin Radiol. 1990; 42:47-9.

4. McGrath FP, Keeling F et al. The role of early sonography in the management of the acute abdomen. Clin Radiol. 1991; 44:1724.

5. Allemann F, Cassina $\mathrm{P}$, Röthlin $\mathrm{M}$, Largiadèr F. Ultrasound scans done by surgeons for patients with acute abdominal pain: a prospective study. Eur J Surg. 1999; 165:966-70.

6. Nural MS, Ceyhan M, Baydin A, Genc S, Bayrak IK, Elmaili M. The role of ultrasonography in the diagnosis and 
management of non traumatic acute abdominal pain.Intern Emerg Med .2008;3 : 349-354.

7. Pablo R. Ros, James E et al. ACR Appropriateness Criteria on Suspected Small-Bowel Obstruction. J Am Coll Radiol. 2006; 3:838-841 .

8. Imran S . Accuracy of ultrasound in the diagnosis of upper abdominal pain. $\mathrm{J}$ Ayub Med Coll Abbottabad. 2003; 15:59-62 .

9. Tsushima Y, Yamada S, Aoki J, Motojima T, Endo K. Effect of contrast-enhanced computed tomography on diagnosis and management of acute abdomen in adults. Clin Radiol. 2002; 57:507-13.

10. MacKersie AB, Lane MJ, Gerhardt RT, Claypool HA, Keenan S, Katz DS, Tucker JE. Nontraumatic acute abdominal pain: unenhanced helical CT compared with three-view acute abdominal series. Radiology. 2005; 237:114-22

11. J Sherck , Shatney C, Sensaki K, Selivanov V. The accuracy of computed tomography in the diagnosis of blunt small- bowel perforation.Am J Surg.1994;168(6):650-5.

12. Maniatis V, Chryssikopoulos H, Roussakis A, Kalamara C , Kavadias S, Papadopoulos A et al. Perforation of the alimentary tract : evaluation with computed tomography. Abdom Imaging. 2000;25:373.

13. Mamel J J. Use of endoscopy in peptic ulcer disease.Med ClinNorth Am. 1991;75(4):841-51.

14. Yildirim D, Hut A, Tatar C, Donmez T , Akinci M, Toptas M. Prognostic factors in patients with acute mesenteric ischemia. Turk J Surg. 2017; 33(2): 104-109.

15. Weir-McCall J, Shaw A, Arya A, Knight A, Howlett DC. The use of pre-operative computed tomography in the assessment of the acute abdomen. Ann R Coll Surg Engl. 2012; 94:102- 7 .
16. Hainaux B, Agneessens E, Bertinotti R, De Maertelaer V, Rubesova E, Capelluto E, et al. Accuracy of MDCT in predicting site of gastrointestinal tract perforation. AJR..2006; 187:1179-83.

17. Foinant M, Lipiecka E, Buc E, Boire JY, Schmidt J, Garcier JM, Pezet D, Boyer L. Impact of computed tomography on patient's care in nontraumatic acute abdomen: 90 patients. J Radiol.2007; 88:559-66. 